\title{
Effect of supplementing fat to pregnant nonlactating cows on colostral fatty acid profile and passive immunity of the newborn calf
}

\author{
M. Garcia, ${ }^{*}$ L. F. Greco, ${ }^{*}$ M. G. Favoreto, ${ }^{*}$ R. S. Marsola, ${ }^{*}$ L. T. Martins, ${ }^{*}$ R. S. Bisinotto, ${ }^{*}$ J. H. Shin, ${ }^{*}$ \\ A. L. Lock, † E. Block, $\ddagger$ W. W. Thatcher, ${ }^{*}$ J. E. P. Santos, ${ }^{*}$ and C. R. Staples ${ }^{* 1}$ \\ *Department of Animal Sciences, University of Florida, Gainesville 32608 \\ †Department of Animal Science, Michigan State University, East Lansing 48824 \\ $\ddagger$ Arm and Hammer Animal Nutrition, Princeton, NJ 08543
}

\section{ABSTRACT}

The objectives were to evaluate the effect of supplementing saturated or unsaturated long-chain fatty acids (FA) to nulliparous and parous Holstein animals ( $\mathrm{n}=$ 78) during late gestation on FA profile of colostrum and plasma of newborn calves and on production and absorption of IgG. The saturated FA supplement (SAT) was enriched in C18:0 and the unsaturated FA supplement (ESS) was enriched in the essential FA C18:2n-6. Fatty acids were supplemented at $1.7 \%$ of dietary dry matter to low-FA diets (1.9\% of dietary dry matter) during the last 8 wk of gestation. Calves were fed $4 \mathrm{~L}$ of colostrum within $2 \mathrm{~h}$ of birth from their own dam or from a dam fed the same treatment. Feeding fat did not affect prepartum dry matter intake, body weight change, or gestation length. Parous but not nulliparous dams tended to give birth to heavier calves if fed fat prepartum. Parous dams were less able to synthesize essential FA derivatives, as evidenced by lower desaturase indices, compared with nulliparous dams, suggesting a greater need for essential FA supplementation. The FA profile of colostrum was modified to a greater degree by prepartum fat feeding than was that of neonatal calf plasma. The placental transfer and synthesis of elongated n-3 FA (C20:5, C22:5, and C22:6) were reduced, whereas the n-6 FA (C18:2, C18:3, and C20:3) were increased in plasma of calves born from dams fed ESS rather than SAT. Supplementing unsaturated FA prepartum resulted in elevated concentrations of trans isomers of unsaturated monoene and diene FA, as well as $\mathrm{C} 18: 2 \mathrm{n}-6$ in colostrum. Serum concentrations of IgG tended to be increased in calves born from dams fed fat compared with those not fed fat, and prepartum feeding of SAT tended to improve circulating concentrations of IgG in newborn calves above the feeding of ESS.

Received May 31, 2013.

Accepted September 29, 2013.

${ }^{1}$ Corresponding author: chasstap@ufl.edu
Apparent efficiency of absorption of IgG was improved in calves born from dams fed fat, and SAT supplementation appeared more effective than supplementation with ESS. Feeding SAT prepartum may be of greater benefit based upon greater circulating IgG concentrations of calves after colostrum feeding. Feeding moderate amounts of saturated or unsaturated long-chain FA during the last 8 wk of gestation changed the FA profile of colostrum and plasma of neonates to reflect that of the supplements.

Key words: dairy calf, fatty acid, colostrum

\section{INTRODUCTION}

The inclusion of fat supplements during the late gestation period is controversial because of a potential decrease in DMI. Using the meta-analysis procedure involving 41 published studies, Onetti and Grummer (2004) reported that supplementing tallow or Ca salts of FA reduced DMI, and that selected hydrolyzed tallow FA tended to reduce DMI of lactating cows regardless of forage source. These prepartum concerns have been based primarily on potential negative carryover effects on postpartum DMI and some metabolic disorders associated with reduced DMI (Drackley, 1999). Saturated and unsaturated fats can affect DMI differently as influenced by amount of supplementation (Onetti et al., 2001) and degree of unsaturation (Relling and Reynolds, 2007). The effects of prepartum fat supplementation on colostrum production and on calf birth weight, FA status, and IgG absorption have received very little study.

Concentrations of the essential FA, C18:2n-6 and C18:3n-3, are much lower in plasma of 120-d-old fetuses compared with that of their ewes (Noble et al., 1985) and in leg muscle phospholipids of 23-kg bovine fetuses compared with that of their dams (Payne, 1978), which may indicate that a marginal deficiency of essential FA exists in the very young until colostrum and milk are consumed. Increased dietary provision of C18:2n-6 during the last 8 wk of gestation dramatically increased 
circulation of C18:2n-6 of the ewe and of the neonate, demonstrating that $\mathrm{C} 18: 2 \mathrm{n}-6$ can be transferred to the fetus through placental tissue (Noble et al., 1978). However, the circulating concentration of the C18:2n-6 derivative, C20:4n-6, was not increased simultaneously in the ewe but was increased in the neonate, indicating that placental or fetal tissues were capable of synthesis of C20:4n-6 from C18:2n-6 (Noble et al., 1978). Therefore, the PUFA profile of neonatal calf plasma reflects both the maternal transfer of preformed PUFA and the synthesis of essential FA derivatives.

Adequate passive transfer (APT) of IgG from gut to circulation is crucial to minimize neonatal morbidity and mortality and strengthen calf immunity (Quigley and Drewry, 1998). Initially, the transportation of the pool of consumed IgG across the intestinal epithelium was documented to occur by nonselective pinocytosis (Lecce, 1965-1966). A major histocompatibility complex class I-related neonatal Fc receptor (FcRn) was discovered in rat enterocytes that aided in the selective transfer of colostral immunoglobulin across the neonate's intestine. Although IgG absorption by the ruminant is FcRn-independent, FcRn likely has a protective effect on circulating IgG to prevent their premature degradation and clearance from circulation across species (Cervenak and Kacskovics, 2009). About 30 to $35 \%$ of the FA in enterocytes are essential FA (Jacobi and Odle, 2012). In addition, cell function involves nanoscale microdomains enriched in cholesterol and glycosphingolipids called lipid rafts, which mainly contain saturated FA $\geq 16$ carbons (Edidin, 2003). In mammals, glycosphingolipids can make up 30 to 40 molar \% of total lipid in the apical plasma membrane of epithelial cells of the small intestine (Degroote et al., 2004). Supplementing long-chain FA prepartum in the saturated and unsaturated forms may influence the FA profile of enterocytes that could affect the transfer of immunoglobulin to plasma of calves. Strategic supplementation of FA in late gestation might change the fluidity of enterocyte membranes, modifying their endocytic activity in addition to potentially modifying the activity of FcRn in the intestine.

The hypothesis of this study was that supplementing prepartum diets with saturated FA or C18:2n-6 would modify the FA profile of colostrum and plasma of newborn calves and that prepartum supplementation of C18:2n-6 would improve efficiency of IgG absorption. Therefore, the objective was to evaluate the effect of supplementing SFA enriched in C18:0 and Ca salts of FA enriched in C18:2n-6 to Holsteins in late gestation on the FA profile of colostrum and plasma of newborn calves and production and transfer of IgG for improving calf immunity.

\section{MATERIALS AND METHODS}

\section{Adult Animal Management and Dietary Treatments}

The experiment was conducted at the University of Florida's dairy farm (Hague, FL). All procedures for animal handling and care were approved by the University of Florida's Animal Research Committee. Nonlactating, pregnant nulliparous $(\mathrm{n}=28)$ and pregnant parous $(\mathrm{n}=50)$ Holsteins were enrolled in the study starting at $8 \mathrm{wk}$ before their calculated parturition date.

Three dietary treatments were the following: no fat supplementation (Control), 1.7\% of dietary DM as mostly free SFA supplement (SAT, Energy Booster 100, Milk Specialties, Dundee, IL), and $2.0 \%$ of dietary DM as Ca salts of FA supplement enriched with essential FA (ESS, Megalac R, Church and Dwight, Princeton, NJ). Fat supplements replaced citrus pulp in the control treatment. Feedstuffs used in the diets were selected for their low concentrations of FA $(1.87 \%$ of $\mathrm{DM})$ and C18:2n-6 (0.38\% of DM; Table 1$)$. The caloric density of the 2 fat-supplemented diets was the same and they were both greater than that of the control diet (Table 1). All dietary treatments were isonitrogenous. Stearic acid made up $49.9 \%$ of the FA in the fat supplement in the SAT treatment, whereas C18:2n-6 was not detected (Table 1). The ESS supplement contained $27.4 \% \mathrm{C} 18: 2 \mathrm{n}-6$ and $4.5 \% \mathrm{C} 18: 0$ of the total FA. The concentration of C16:0 was similar in both supplements.

Between wk -8 and -4 relative to calving, animals were housed in sod-based pens and fed as separate groups according to their dietary treatments. At wk 4 before the expected calving date, animals were moved to a sod-based pen equipped with Calan gates (American Calan Inc., Northwood, NH), and daily DMI was measured individually. Animals were weighed using a digital scale at 8 and $4 \mathrm{wk}$ before the calculated parturition date and at calving. At the same time, body condition was scored by the same person using a 5-point scale divided into 0.25-point increments (Elanco, 1996).

Prepartum diets were prepared as a TMR and offered once daily $(1000 \mathrm{~h})$. Feed offered was adjusted daily to achieve 5 to $10 \%$ orts. Orts were collected and weighed daily. A sample of bermudagrass silage was collected once a week and analyzed for DM by drying in a forced-air oven at $55^{\circ} \mathrm{C}$ for $48 \mathrm{~h}$ to maintain the formulated DM ratio of forage to concentrate (Table 1). Silage samples collected once weekly were dried and ground through a 1-mm screen using a Wiley mill (Arthur H. Thomas, Philadelphia, PA) and composited every $4 \mathrm{wk}$. Samples of concentrate mixtures were collected once weekly and composited monthly. Forage and concentrates were analyzed for ash $\left(600^{\circ} \mathrm{C}\right.$ for 2 
Table 1. Ingredient and chemical composition of experimental diets fed to pregnant Holstein animals starting 8 wk before calculated parturition date

\begin{tabular}{|c|c|c|c|}
\hline \multirow[b]{2}{*}{ Item } & \multicolumn{3}{|c|}{ Dietary treatment ${ }^{1}$} \\
\hline & Control & SAT & ESS \\
\hline \multicolumn{4}{|l|}{ Ingredient, $\%$ of DM } \\
\hline Bermuda silage & 56.0 & 56.0 & 56.0 \\
\hline Ground barley & 8.0 & 8.0 & 8.0 \\
\hline Peanut meal & 10.0 & 10.0 & 10.0 \\
\hline Citrus pulp & 21.9 & 20.2 & 19.9 \\
\hline Saturated fatty acids ${ }^{2}$ & - & 1.7 & - \\
\hline Ca salts of fatty acids ${ }^{3}$ & - & - & 2.0 \\
\hline Mineral $\operatorname{mix}^{4}$ & 4.1 & 4.1 & 4.1 \\
\hline \multicolumn{4}{|l|}{$\begin{array}{l}\text { Nutrient composition } \\
\text { (DM basis) }\end{array}$} \\
\hline $\mathrm{NE}_{\mathrm{L}},{ }^{5} \mathrm{Mcal} / \mathrm{kg}$ & 1.42 & 1.49 & 1.5 \\
\hline $\mathrm{CP}, \%$ of $\mathrm{DM}$ & 14.0 & 13.9 & 14.1 \\
\hline $\mathrm{NDF}, \%$ of DM & 47.0 & 48.2 & 47.4 \\
\hline $\mathrm{ADF}, \%$ of $\mathrm{DM}$ & 25.6 & 25.3 & 25.5 \\
\hline Fatty acids, $\%$ of DM & 1.87 & 3.42 & 3.50 \\
\hline $\mathrm{C} 18: 0, \%$ of $\mathrm{DM}$ & 0.06 & 0.86 & 0.12 \\
\hline $\mathrm{C} 18: 2 \mathrm{n}-6, \%$ of DM & 0.38 & 0.37 & 0.83 \\
\hline $\mathrm{Ca}, \%$ of $\mathrm{DM}$ & 1.41 & 1.47 & 1.67 \\
\hline $\mathrm{P}, \%$ of $\mathrm{DM}$ & 0.29 & 0.28 & 0.30 \\
\hline $\mathrm{Mg}, \%$ of $\mathrm{DM}$ & 0.38 & 0.38 & 0.41 \\
\hline $\mathrm{K}, \%$ of $\mathrm{DM}$ & 1.35 & 1.34 & 1.34 \\
\hline $\mathrm{Cl}, \%$ of DM & 0.76 & 0.76 & 0.80 \\
\hline $\mathrm{Na}, \%$ of $\mathrm{DM}$ & 0.17 & 0.17 & 0.20 \\
\hline
\end{tabular}

${ }^{1}$ Control = no fat supplement; SAT $=$ SFA supplement; ESS = essential fatty acid supplement.

${ }^{2}$ Energy Booster 100 (Milk Specialties, Dundee, IL).Total fatty acids, 94\% of DM. Fatty acid profile: C8:0 = $0.77 \%, \mathrm{C} 10: 0=0.36 \%, \mathrm{C} 12: 0=0.68 \%, \mathrm{C} 14: 0=4.61 \%, \mathrm{C} 15: 0=0.61 \%, \mathrm{C} 16: 0=36.2 \%, \mathrm{C} 17: 0=1.79 \%, \mathrm{C} 18: 0$ $=49.9 \%, \mathrm{C} 20: 0=0.78$, others $=3.8 \%$ (C16:1, C18:1, C18:2 n-6, and C18:3 n-3 were not detected $)$.

${ }^{3}$ Megalac-R (Church \& Dwight, Princeton, NJ). Fatty acid profile: C12:0 =0.30\%, C14:0 = 0.75\%, C16:0 = $34.3 \%, \mathrm{C} 16: 1=0.14 \%, \mathrm{C} 17: 0=0.13 \%, \mathrm{C} 18: 0=4.54 \%, \mathrm{C} 18: 1=27.1 \%, \mathrm{C} 18: 2 \mathrm{n}-6=27.4 \%, \mathrm{C} 18: 3 \mathrm{n}-3=2.27 \%$, others $=2.81 \%(\mathrm{C} 8: 0, \mathrm{C} 10: 0$, and $\mathrm{C} 15: 0$ were not detected $)$.

${ }^{4}$ Contained (DM basis) $34.5 \%$ corn meal, $5.0 \%$ dicalcium phosphate, $16.0 \%$ calcium carbonate, $10 \%$ calcium sulfate, $5 \%$ magnesium oxide, $10 \%$ magnesium sulfate, $4 \%$ sodium chloride, $1.7 \%$ Zinpro 4-plex (Zinpro, Minneapolis, MN), 0.4\% Rumensin 80 (Elanco Animal Health, Indianapolis, IN), 0.35\% Sel-Plex 2000 (Alltech Biotechnology, Nicholasville, KY), $0.002 \%$ Ca iodate, and a vitamin premix. Each kilogram contained $24.5 \%$ $\mathrm{CP}, 9.8 \% \mathrm{Ca}, 1.5 \% \mathrm{P}, 4.2 \% \mathrm{Mg}, 3.2 \% \mathrm{~S}, 1.7 \% \mathrm{Na}, 10.7 \% \mathrm{Cl}, 475 \mathrm{mg}$ of Zn, $160 \mathrm{mg}$ of Cu, $456 \mathrm{mg}$ of $\mathrm{Mn}, 7.4$ $\mathrm{mg}$ of Se, $37.4 \mathrm{mg}$ of Co, $13.2 \mathrm{mg}$ of I, 118,000 IU of vitamin A, 27,500 IU of vitamin D, 2,600 IU of vitamin $\mathrm{E}$, and $770 \mathrm{mg}$ of monensin.

${ }^{5}$ Net energy of diets calculated considering $12 \mathrm{~kg} / \mathrm{d}$ of DMI (CPM Dairy, version 3.0.8; Cornell University, Ithaca, NY; Penn State University, University Park, PA; The Miner Institute, Chazy, NY).

h) and NDF and ADF according to Van Soest et al. (1991) using an Ankom 200 Fiber Analyzer (Ankom, Macedon, NY). Heat-stable $\alpha$-amylase and sulfite were used in the NDF assay. Nitrogen concentration was determined using a Vario MAX CN Macro Elementar Analyzer (Elementar Analysensysteme GmbH, Hanau, Germany). Protein concentration was calculated by multiplying $\mathrm{N} \times 6.25$. Concentrations of FA in dietary treatments were determined using gas chromatography as described for plasma below.

\section{Management of Calves}

Calves were born between December 24, 2008, and April 5, 2009. Calves were born in a sod-based pen. All dams were monitored for signs of calving initiation every 30 min between 0530 to $1530 \mathrm{~h}$ and then every 2 $\mathrm{h}$ between 1530 and $0530 \mathrm{~h}$. Within $2 \mathrm{~h}$ of birth, calves were weighed and ear-tagged, and the umbilical cord was disinfected with $10 \%$ Betadine solution (Purdue Frederick Co., Norwalk, CT). Calves were housed temporarily in individual pens $(1 \times 1 \mathrm{~m})$ equipped with a heat lamp before moving to individual wire pens $(1 \times$ $1.5 \mathrm{~m}$ ) bedded with sand between 6 to $16 \mathrm{~h}$ of age.

Within $2 \mathrm{~h}$ of birth, dams were milked with a cow-side vacuum pump. Colostrum quality was recorded using a colostrometer (Biogenics, Mapleton, OR). Immediately after weighing calves, $4 \mathrm{~L}$ of colostrum from their own dam, regardless of IgG concentration, was delivered using an esophageal feeding tube. When a dam did not produce sufficient colostrum for her calf, colostrum from another dam fed the same prepartum treatment 
was used to feed that calf. Remnant colostrum $(>1$ $\mathrm{L}$ and $>50 \mathrm{~g}$ of $\operatorname{IgG} / \mathrm{L}$ ) after calf feeding was frozen $\left(-4^{\circ} \mathrm{C}\right)$ to feed calves born to dams that produced $<4 \mathrm{~L}$ of colostrum. Whole colostrum samples were collected and frozen $\left(-20^{\circ} \mathrm{C}\right)$ for later analyses.

Calves were bled via jugular venipuncture before colostrum feeding for harvest of plasma using heparin as an anticoagulant and harvest of serum without anticoagulant (Vacutainer, Becton Dickinson, Franklin Lakes, NJ). Between 24 and $30 \mathrm{~h}$ after colostrum feeding, blood samples were collected again for harvest of serum. Serum was allowed to clot at room temperature for 2 to $4 \mathrm{~h}$. All tubes of blood were centrifuged at 2,095 $\times g$ for 15 min at $4^{\circ} \mathrm{C}$ (Allegra X-15R centrifuge, Beckman Coulter Inc., Brea, CA) and supernatant frozen at $-20^{\circ} \mathrm{C}$.

\section{Analysis of Colostrum and Blood Samples}

Colostrum from each dam and serum samples of newborn calves were measured for bovine total IgG concentration by single radial immunodiffusion (Cat. No. 240-60, VMRD Inc., Pullman, WA). Colostrum and serum samples were diluted $1: 5$ and $3: 4$, respectively, with double distilled water. Diluted samples $(3 \mu \mathrm{L})$ were applied to serial radial immunodiffusion plates containing agarose gel with anti-bovine IgG. Plates containing the samples were left undisturbed for $23 \mathrm{~h}$ at room temperature. Resulting ring diameters were measured with a monocular comparator (VMRD Inc.). A standard curve was plotted with reference sera $(4,8,16$, and $32 \mathrm{~g}$ of $\mathrm{IgG} / \mathrm{L})$ supplied by the manufacturer. Intra- and interassay CV were 3.0 and $3.3 \%$, respectively. Serum total protein (STP) concentrations were determined before freezing of serum samples, using an automatic temperature-compensated hand refractometer (Reichert Jung; Cambridge Instruments Inc., Buffalo, NY).

A frozen whole colostrum sample $(\sim 100 \mathrm{~mL})$ from each dam was freeze-dried (Labconco, Kansas City, $\mathrm{MO}$ ) and analyzed for FA. Total FA concentration and FA profile from freeze-dried colostrum samples were determined using a modification of the 2-step methylation method developed by Kramer et al. (1997). One milliliter of C17:1 cis-10 (1:1 mg/mL of toluene) was added as the internal standard to $175 \mathrm{~g}$ of freeze-dried colostrum. Two milliliters of $0.5 \mathrm{M}$ sodium methoxide solution was added to the sample and incubated for 10 min at $50^{\circ} \mathrm{C}$. Three milliliters of $5 \%$ methanolic $\mathrm{HCl}$ was added and samples were incubated at $80^{\circ} \mathrm{C}$ for $10 \mathrm{~min}$. Samples were neutralized with a $6 \%$ aqueous potassium carbonate solution and FA methyl esters (FAME) extracted using $n$-hexane. The solvent layer was dried over anhydrous sodium sulfate; FAME were then used for GLC analysis. The FA composition was determined by using a GC-2010 Plus gas chromatograph (Shimadzu, Kyoto, Japan) with a split injector (1:100 split ratio) and a flame-ionization detector using a CP-Sil 88 WCOT (wall-coated open tubular) fused-silica column $(100 \mathrm{~m} \times 0.25 \mathrm{~mm}$ i.d. $\times 0.2-\mu \mathrm{m}$ film thickness; Varian Inc., Lake Forest, CA). The GLC conditions were described by Kramer et al. (2001). The FAME were identified by comparison of retention times with known FAME standards (Supelco 37 component FAME mix, cis/trans FAME mix, bacterial acid methyl ester mix, and PUFA No. 3 mix from Supelco Inc., Bellefonte, PA; GLC reference standard 463 and conjugated C18:2 mixture \#UC-59 M from Nu-Chek Prep, Elysian, MN). Short-chain FAME were corrected for mass discrepancy using the correction factors published by Ulberth and Schrammel (1995).

Methylation of the FA from plasma of newborn calves was performed by the 2-step methylation procedure according to Kramer et al. (2001) with some modifications. One milliliter of internal standard (C19:0, $1 \mathrm{mg} /$ $\mathrm{mL}$ of benzene) was added to calculate total FA concentration. The FAME were determined using a Varian CP-3800 gas chromatograph (Varian Inc., Palo Alto, CA) according to Kim et al. (2007).

Calves were considered to have APT if serum concentration of total IgG was $\geq 10 \mathrm{~g} / \mathrm{L}$ after $24 \mathrm{~h}$ of colostrum feeding (Tyler et al., 1996). The apparent efficiency of IgG absorption (AEA, \%) was calculated according to Quigley et al. (1998) using the following equation: $\operatorname{IgG}$ concentration in serum at $24 \mathrm{~h}$ of life $(\mathrm{g} / \mathrm{L}) \times[0.099$ $\times \mathrm{BW}(\mathrm{kg})$ at birth] $/ \mathrm{IgG}$ intake $(\mathrm{g})$. Serum volume of each Holstein calf was estimated at $9.9 \%$ of birth weight. Additionally, STP concentrations $\geq 5.0 \mathrm{~g} / \mathrm{dL}$ was used as an indicator of APT (Tyler et al., 1996).

\section{Statistical Analysis}

The experiment was a randomized complete block design. At 8 wk before the calculated calving date, a weekly cohort of animals (average of 5) was blocked based on parity (nulliparous and parous) and BCS and, within each block, was assigned randomly to 1 of 3 treatments. Test of block in the model was not significant and was thus deleted. Dependent variables with more than one observation within experimental unit were analyzed as repeated measures using the generalized linear mixed-model GLIMMIX procedure of SAS (SAS/STAT version 9.2; SAS Institute Inc., Cary, NC).

Data were tested for normality of residuals using the Shapiro-Wilk test (SAS version 9.2, SAS Inst. Inc.) and transformation was performed to achieve normality as needed. Repeated measures were tested to determine the structure of best fit as indicated by the smallest 
Schwartz Bayesian information criterion. Different temporal responses to treatments were further examined using the SLICE option of the MIXED or GLIMMIX procedure. Cow nested within treatment and parity was used as a random term. The following model was used:

$$
\begin{aligned}
\mathrm{Y}_{\mathrm{ijkl}}=\mu+ & \left.\mathrm{T}_{\mathrm{i}}+\mathrm{P}_{\mathrm{j}}+(\mathrm{TP})_{\mathrm{ij}}+\mathrm{C}_{(\mathrm{ij}}\right)_{\mathrm{k}}+\mathrm{D}_{\mathrm{l}}+(\mathrm{TD})_{\mathrm{il}} \\
& +(\mathrm{PD})_{\mathrm{jl}}+(\mathrm{TPD})_{\mathrm{ijl}}+\mathrm{E}_{\mathrm{ijkl}},
\end{aligned}
$$

where $\mathrm{Y}_{\mathrm{ijkl}}=$ dependent variable; $\mu=$ overall mean; $\mathrm{T}_{\mathrm{i}}$ $=$ fixed effect of treatment i (control, SAT, and ESS); $\mathrm{P}_{\mathrm{j}}=$ effect of parity $\mathrm{j}$ (nulliparous and parous); (TP) ${ }_{\mathrm{ij}}=$ effect of treatment $\times$ parity interaction; $\mathrm{C}\left({ }_{\mathrm{ij}}\right)_{\mathrm{k}}=$ random effect of dam $\mathrm{k}$ nested within treatment and parity $(\mathrm{k}=1,2,3, \ldots, \mathrm{n}) ; \mathrm{D}_{1}=$ effect of day 1 relative to calving $(1=-14,-13, \ldots, 0)$; $(\mathrm{TD})_{\mathrm{il}}=$ effect of treatment $\times$ day interaction; $(\mathrm{PD})_{\mathrm{j} 1}=$ effect of parity $\times$ day interaction; $(\mathrm{TPD})_{\mathrm{ij} \mathrm{l}}=$ effect of treatment $\times$ parity $\times$ day interaction; and $\mathrm{E}_{\mathrm{ijkl}}=$ residual error.

For nonrepeated measures regarding dams, the preceding model was used after removing day and interactions with day. All calf variables were single measures and were analyzed with the MIXED procedure of SAS. Calf nested within treatment and parity was a random term. The statistical model for the analysis was

$$
\begin{gathered}
Y_{\mathrm{ijkl}}=\mu+\mathrm{T}_{\mathrm{i}}+\mathrm{P}_{\mathrm{j}}+\mathrm{G}_{\mathrm{k}}+\mathrm{C}\left(\mathrm{(ijk}_{\mathrm{ijk}}\right)_{1}+(\mathrm{TP})_{\mathrm{ij}} \\
+(\mathrm{TG})_{\mathrm{ik}}+(\mathrm{PG})_{\mathrm{jk}}+(\mathrm{TPG})_{\mathrm{ijk}}+\mathrm{E}_{\mathrm{ijk} \mathrm{kl}},
\end{gathered}
$$

where $\mathrm{Y}_{\mathrm{ijk}}=$ dependent variable; $\mu=$ overall mean; $\mathrm{T}_{\mathrm{i}}$ $=$ fixed effect of treatment $\mathrm{i}$ (control, SAT, and ESS); $\mathrm{P}_{\mathrm{j}}=$ effect of parity $\mathrm{j}$ (nulliparous and parous); $\mathrm{G}_{\mathrm{k}}$ $=$ effect of sex $\mathrm{k}$ (male and female); $\mathrm{C}\left({ }_{\mathrm{ijk}}\right)_{1}=$ random effect of calf 1 nested within treatment, parity, and $\operatorname{sex}(1,2,3, \ldots, \mathrm{n}) ;(\mathrm{TP})_{\mathrm{ij}}=$ effect of treatment $\times$ parity interaction; $(\mathrm{TG})_{\mathrm{ik}}=$ effect of treatment $\times$ sex interaction; $(\mathrm{PG})_{\mathrm{jk}}=$ effect of parity $\times$ sex interaction; $(\mathrm{TPG})_{\mathrm{ijk}}=$ effect of treatment $\times$ parity $\times$ sex interaction; and $\mathrm{E}_{\mathrm{ijkl}}=$ residual error.

Appropriate preplanned orthogonal contrasts were performed for dam-dependent variables. Two treatment contrasts were as follows: (1) fat supplement (FAT): control versus (SAT + ESS), and (2) FA supplement (FAS): ESS versus SAT. Single degree of freedom contrasts of the 2 treatment contrasts with parity were performed. For calf-dependent variables, single degree of freedom contrasts of the 2 dam treatment contrasts with calf sex were performed. If test of a 2- or 3-way interaction was $P>0.25$, the interaction was dropped from the model (Bancroft, 1968). Occasionally, treatment means separation (PDIFF option of SAS) was conducted to assist in the interpretation of results. Co- efficients of correlation were estimated using the CORR procedure of SAS to describe the relationships between and within cow and calf variables. Differences discussed in the text were significant at $P \leq 0.05$ and tended to be significant at $0.05<P \leq 0.10$.

\section{RESULTS AND DISCUSSION}

\section{Prepartum Cow Performance}

Dams consumed their assigned dietary treatment for a mean of $55 \mathrm{~d}$, not differing among dietary treatments or between parities (Table 2). Mean BW and BCS were not different among treatments at enrollment $(614 \mathrm{~kg}$ and 3.34 , respectively) or at calving (668 $\mathrm{kg}$ and 3.40 , respectively). Animals gained on average $54.3 \mathrm{~kg}$ of BW and had a 0.06-unit increase in BCS between enrollment and calving, but changes did not differ among treatments. As expected, nulliparous dams had a shorter gestation period $(3.3 \mathrm{~d})$ and weighed $178 \mathrm{~kg}$ less than parous dams at calving $(P<0.01)$, but measures were not affected by FAS supplementation.

Of the 78 animals enrolled, only 70 produced colostrum immediately after calving. The IgG concentration in colostrum was greater in parous dams fed fat compared with control dams (115 vs. $96 \mathrm{~g} / \mathrm{L}$ ), whereas that of nulliparous dams was reduced by prepartum fat supplementation compared with control dams (102 vs. $83 \mathrm{~g} / \mathrm{L} ;$ FAT $\times$ parity interaction, $P=0.05)$. Feeding oilseeds prepartum to Angus and Hereford heifers did not affect IgG concentration of colostrum (Dietz et al., 2003), although diets were isocaloric in their study, unlike the current study.

Sixty-one of the 78 dams provided at least $14 \mathrm{~d}$ of DMI data prepartum (Table 2). Daily DMI was consistent over time until the last 1 to $2 \mathrm{~d}$ before parturition, at which time DMI decreased 30 to $40 \%$ (effect of day relative to calving, $P<0.01$; Figure 1$)$. As expected, intakes of DM (11.8 vs. $10.0 \mathrm{~kg} / \mathrm{d})$ and $\mathrm{NE}_{\mathrm{L}}(17.2$ vs. 14.8 Mcal/d) were greater $(P<0.01)$ for parous compared with nulliparous dams. Intake of C18:2n-6 was 43,42 , and $87 \mathrm{~g} / \mathrm{d}$ and that of C18:0 was 7, 97, and $14 \mathrm{~g} / \mathrm{d}$ for dams fed control, SAT, and ESS dietary treatments, respectively. Neither supplementing FA prepartum nor the type of FA fed affected mean DMI, although animals fed ESS consumed $0.9 \mathrm{~kg} / \mathrm{d}$ less DM compared with animals fed SAT. This decrease was similar to the mean decrease of $1.0 \mathrm{~kg} / \mathrm{d}$ in DMI when Ca salts of palm FA were fed at an average of $3.8 \%$ of dietary DM ( $\mathrm{n}=23$ studies; Onetti and Grummer, 2004). Similarly, DMI was not different between prepartum dairy cows fed a saturated or a Ca salt of an unsaturated fat source at $<2 \%$ of dietary DM, although DMI was $1.2 \mathrm{~kg} / \mathrm{d}$ less for cows fed the Ca salt FA (Caldari-Torres et al., 2011). 
Table 2. Performance of nulliparous (Null) and parous Holstein animals not supplemented (control) or supplemented with saturated (SAT) or essential (ESS) fatty acids starting 8 wk before calculated parturition date

\begin{tabular}{|c|c|c|c|c|c|c|c|c|c|c|c|c|}
\hline \multirow{2}{*}{ Measure } & \multicolumn{6}{|c|}{ Dietary treatment ${ }^{1}$ and parity $(\mathrm{P})$} & \multirow{2}{*}{ SEM } & \multirow{2}{*}{ FAT } & \multicolumn{3}{|c|}{$P$-value ${ }^{2}$} & \multirow{2}{*}{$\begin{array}{l}\text { FAS } \\
\times P\end{array}$} \\
\hline & \multicolumn{2}{|c|}{ Control } & \multicolumn{2}{|c|}{ SAT } & \multicolumn{2}{|c|}{ ESS } & & & & & & \\
\hline Number of dams ${ }^{3}$ & 8 & 17 & 11 & 16 & 9 & 17 & & & & & & \\
\hline Days fed diets & 54.6 & 54.4 & 54.8 & 56.7 & 53.7 & 57.2 & 1.6 & 0.44 & 0.85 & 0.20 & 0.30 & 0.59 \\
\hline BW at enrollment, $\mathrm{kg}$ & 538 & 694 & 511 & 709 & 532 & 701 & 24 & 0.91 & 0.80 & $<0.01$ & 0.52 & 0.54 \\
\hline BCS at calving & 3.31 & 3.51 & 3.36 & 3.41 & 3.44 & 3.38 & 0.07 & 0.82 & 0.68 & 0.30 & 0.10 & 0.45 \\
\hline BW change, $\mathrm{kg}$ & 49.4 & 58.4 & 57.2 & 67.6 & 50.7 & 42.4 & 12.7 & 0.96 & 0.21 & 0.72 & 0.73 & 0.46 \\
\hline BCS change, $\mathrm{kg}$ & -0.03 & 0.04 & 0.00 & 0.14 & 0.14 & 0.06 & 0.08 & 0.25 & 0.70 & 0.47 & 0.74 & 0.14 \\
\hline Gestation length, d & 275 & 276 & 275 & 278 & 273 & 279 & 1 & 0.25 & 0.62 & $<0.01$ & 0.19 & 0.28 \\
\hline Number of dams ${ }^{4}$ & 8 & 16 & 7 & 16 & 8 & 15 & & & & & & \\
\hline IgG colostrum, g/L & 102 & 96 & 83 & 122 & 83 & 109 & 11 & 0.99 & 0.59 & 0.04 & 0.05 & 0.56 \\
\hline Number of dams ${ }^{5}$ & 4 & 16 & 8 & 13 & 6 & 14 & & & & & & \\
\hline
\end{tabular}

${ }^{1}$ Control = no fat supplement; SAT = Energy Booster 100 (Milk Specialties, Dundee, IL); ESS = Megalac-R (Church \& Dwight, Princeton, NJ).

${ }^{2} P$-values for orthogonal contrasts and interactions; FAT $=$ control vs. (SAT + ESS), FAS $=$ ESS vs. SAT. Effect of day or week relative to calving and their interactions with treatments were not significant unless footnoted.

${ }^{3}$ Dams that provided calves for calculation of IgG absorption efficiency.

${ }^{4}$ Dams from which colostrum was collected.

${ }^{5}$ Animals that provided $14 \mathrm{~d}$ of DMI data via the Calan gate system (American Calan, Northwood, NH) before calving.

${ }^{6}$ Effect of days relative to calving, $P<0.01$.

\section{FA Profile of Plasma of Calves at Birth Before Colostrum Intake}

Mean plasma concentrations of total FA at birth ranged from 1.14 to $1.37 \mathrm{mg} / \mathrm{mL}$ (Table 3), which are similar to those reported by Jenkins et al. (1988) for 3 -d-old dairy calves. Consumption of approximately $185 \mathrm{~g} / \mathrm{d}$ more FA by dams fed SAT or ESS for $55 \mathrm{~d}$ before calving compared with dams fed control did not

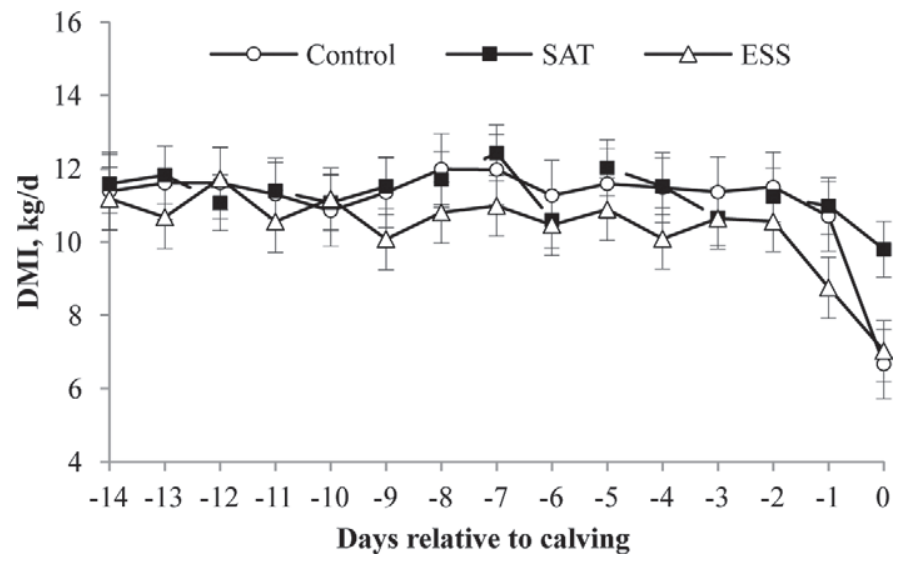

Figure 1. Dry matter intake of nulliparous (null) and parous Holstein cows not supplemented (Control) or supplemented with saturated (SAT) or essential (ESS) fatty acids starting 8 wk before calculated calving date. Effect of day relative to calving, $P<0.01$. result in elevated circulating concentrations of FA or in changes in the FA profile of plasma in their newborn calves (Table 3). However, the type of FA fed prepartum tended $(P=0.10)$ to affect the total concentration of plasma FA, with a greater concentration of FA in plasma of calves born from dams fed ESS instead of SAT (1.36 vs. $1.22 \mathrm{mg} / \mathrm{mL}$ ).

The source of fat supplement fed prepartum did change the FA profile of plasma of newborns. The ESS supplement used in the current study is partially protected from hydrolysis and hydrogenation in the rumen because it is in the Ca salt form (Klusmeyer and Clark, 1991); therefore, a greater amount of C18:2n-6 should have reached the intestine for absorption and potential transfer to the fetus compared with the other treatments. Although not significant $(P=0.12)$, calves born from dams consuming an additional $43 \mathrm{~g} / \mathrm{d}$ of C18:2n-6 had a numerically greater proportion of their plasma FA as C18:2n-6 compared with calves born from dams fed SAT (4.10 vs. 3.28\% of FA). When ovine and caprine dams were fed formaldehyde-treated soybeans (reduction in microbial hydrogenation of C18:2n-6) prepartum, the proportions of $\mathrm{C} 18: 2 \mathrm{n}-6$ and $\mathrm{C} 20: 4 \mathrm{n}-6$ of all plasma lipid fractions of newborns were increased (Noble et al., 1978; Soares, 1986). Of the C18:2n-6 derivatives, the plasma proportions of $\mathrm{C} 18: 3 \mathrm{n}-6$ of calves born from both parities $(0.27$ vs. $0.17 \% ; P=0.04)$ and that of C20:3n- 6 of calves born from parous dams only 
Table 3. Mean concentrations of fatty acids (FA) in plasma of newborn Holstein calves born from nulliparous (Null) and parous Holstein animals $(\mathrm{n}=78)$ not supplemented (control) or supplemented with saturated (SAT) or essential (ESS) fatty acids starting 8 wk before calculated parturition date

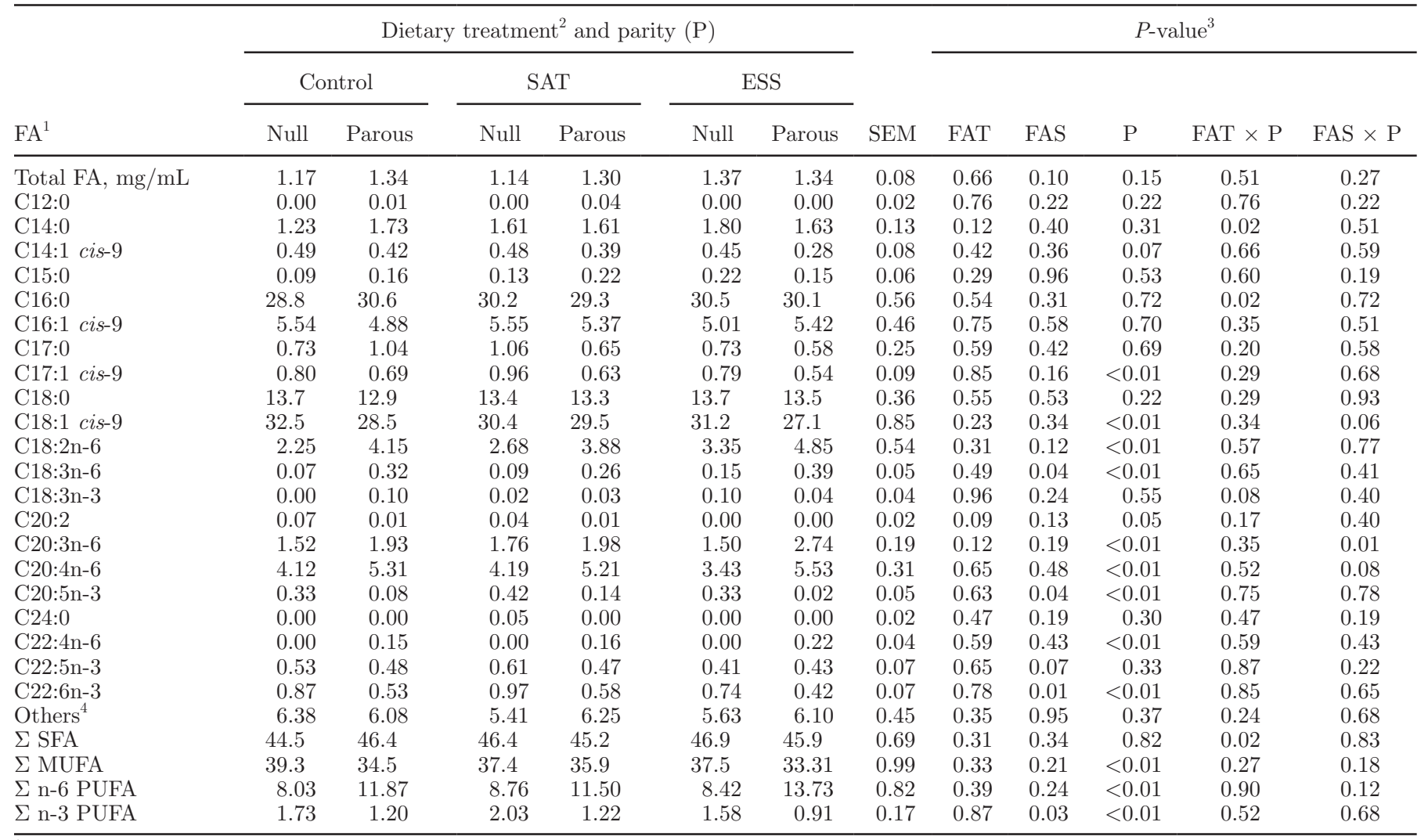

${ }^{1}$ Proportion of total FA (g/100 g of total FA) unless otherwise indicated.

${ }^{2}$ Control = no fat supplement; SAT = Energy Booster 100 (Milk Specialties, Dundee, IL); ESS = Megalac-R (Church \& Dwight, Princeton, NJ). ${ }^{3} P$-values for orthogonal contrasts and interactions: FAT $=$ control vs. (SAT + ESS), FAS $=$ ESS vs. SAT. Interactions with sex were not significant unless footnoted.

${ }^{4}$ Unidentified FA.

( 2.74 vs. $1.98 \%$; FAS by parity interaction, $P=0.01$ ) were increased when ESS compared with SAT was fed prepartum. Overall, the n-6 PUFA concentrations in plasma of newborn calves is greatly reduced compared with that of adult cows, especially the concentration of C18:2n-6 (Moallem and Zachut, 2012).

Although the proportion of the parent n-3 PUFA, C18:3n-3, was unchanged in calf plasma by dietary treatment, proportions of all C18:3n-3 derivatives were decreased or tended to be decreased in calves born from dams supplemented with ESS compared with SAT, including C20:5n-3 (0.17 vs. $0.28 \%$ of FA, $P=$ $0.04), \mathrm{C} 22: 5 \mathrm{n}-3$ (0.42 vs. $0.54 \%$ of FA, $P=0.07$ ), and C22:6n-3 (0.58 vs. $0.77 \%$ of FA, $P=0.01$; Table 3). When considering the group of n-3 PUFA, the concentration was decreased $(P=0.03)$ from 1.62 to $1.24 \%$ when supplementing with ESS compared with SAT. The n-3 PUFA, especially C22:6n-3, are very important to the development of the central nervous system of neonates (Bradbury, 2011). It is unknown whether these reductions in n-3 PUFA by ESS supplementation would compromise cognitive function in calves born from dams fed ESS. These FA changes in plasma were similar to those reported for healthy men fed additional amounts of $\mathrm{C} 18: 2 \mathrm{n}-6$ with an unchanging intake of C18:3n-3; namely, that circulating concentrations of $\mathrm{C} 18: 2 \mathrm{n}-6$ were increased, those of $\mathrm{C} 20: 4 \mathrm{n}-6$ were unchanged, and those of $\mathrm{C} 20: 5 \mathrm{n}-3$ and $\mathrm{C} 22: 6 \mathrm{n}-3$ were decreased in the phospholipid fraction (Liou et al., 2007).

This inverse relationship of C18:2n-6 and n-3 derivatives may result from a reduction in desaturation of C18:3n-3 due to greater competition of C18:2 n- 6 for $\Delta^{6}$-desaturase. In the current study, the activity of $\Delta^{6}$ - and $\Delta^{5}$-desaturases was estimated by calculating the desaturase indices according to Loor and Herbein (2003). A lower activity of these enzymes was detected for synthesis of $\mathrm{C} 20: 4 \mathrm{n}-6(P=0.03)$ and $\mathrm{C} 20: 5 \mathrm{n}-3(P=$ $0.01)$ but not of $\mathrm{C} 22: 5 \mathrm{n}-3(P=0.12)$ and $\mathrm{C} 22: 6 \mathrm{n}-3(P$ $=0.19$, Table 4$)$ in placenta of dams fed ESS instead 
of SAT. Therefore, increased competition for $\Delta^{6}$ - and $\Delta^{5}$-desaturases by an increased supply of C18:2n-6 was only partly true, as evidenced by a reduced index for C20:5n- 3 but not C22:5n-3 and C22:6n-3. The decreased index for C20:4n-6 may reflect the greater supply of C18:2n-6 without a change in $\mathrm{C} 20: 4 \mathrm{n}-6$ concentration in plasma. That is, the same amount of C20:4n-6 was synthesized from C18:2n-6 with decreased activity of $\Delta^{6}$ - and $\Delta^{5}$-desaturases because of a greater supply of C18:2n-6. Loor and Herbein (2003) also reported a lower normalized ratio of $\mathrm{C} 20: 4 \mathrm{n}-6$ to $\mathrm{C} 18: 2 \mathrm{n}-6$ in milk fat of cows fed more C18:2n-6 using safflower oil. The current finding of reduced proportions of $\mathrm{C} 18: 3 \mathrm{n}-3$ derivatives in plasma of calves born from ESS-supplemented dams is opposite to that of Elmes et al. (2004), who reported that increased intake of C18:2n- 6 by pregnant ewes not only increased the proportion of C18:2n-6, C18:3n- 6 , C20:3n-6, and C20:4n-6, but also that of C22:5n-3 and C22:6n-3 in plasma phosphatidylcholine of the unborn fetuses, although the current study considered total FA and not just phospholipids. These authors suggested that the activity of FA desaturases and elongases increased in the liver of fetuses when ewes were fed more C18:2n- 6 so that the synthesis of both $n-6$ and n-3 PUFA derivatives was enhanced.

Although parities did not differ in total FA concentration in plasma, the proportions of specific circulating FA did differ between parities (Table 3). The proportion of total SFA was greater in calves born from nulliparous dams fed fat compared with those not fed fat (46.6 vs. $44.5 \%$ of FA), whereas calves born from parous dams did not differ in SFA proportions due to fat supplementation ( 45.2 vs. $46.4 \%$ of FA; parity by FAT interaction, $P=0.02$ ). This interaction was due primarily to greater $(P=0.02)$ proportions of C14:0 (1.70 vs. $1.23 \%$ of FA for nulliparous compared with 1.62 vs. $1.73 \%$ of FA for parous dams) and C16:0 (30.3 vs. $28.8 \%$ of FA for nulliparous compared with 1.62 vs. $1.73 \%$ of FA for parous dams). Compared with calves born from parous dams, calves born from nulliparous dams had greater $(P<0.01)$ proportions of total n-9 MUFA (38.1 vs. $34.6 \%$ of FA, specifically C14:1, C17:1, and $\mathrm{C} 18: 1$ ) and total n-3 PUFA (1.8 vs. $1.1 \%$ of FA, specifically $\mathrm{C} 20: 5$ and $\mathrm{C} 22: 6)$ but lesser proportions of total n-6 PUFA (8.4 vs. $12.4 \%$ of FA, specifically C18:2, C18:3, C20:3, C20:4, and C22:4) in plasma. Nulliparous dams may have passed more n-3 FA derivatives on to their calves than parous dams because, before the study, they were on pasture and consumed fresh grass that has greater concentrations of n-3 FA than stored forage (Dewhurst et al., 2006). In addition, the n-3 FA status of dams may decrease with increasing parity, as reported in humans (Al et al., 1997), and thus account for the reduction in n-3 derivatives in blood of young born to older dams. If activities of desaturase and elongase enzymes are decreased with increasing age, supplementation of essential FA may be more important to older cows.

Table 4. Normalized ratios of fatty acids in plasma of newborn and colostrum produced by nulliparous (Null) and parous Holstein animals $(\mathrm{n}=$ 70) not supplemented (control) or supplemented with saturated (SAT) or essential (ESS) fatty acids starting 8 wk before calculated parturition date

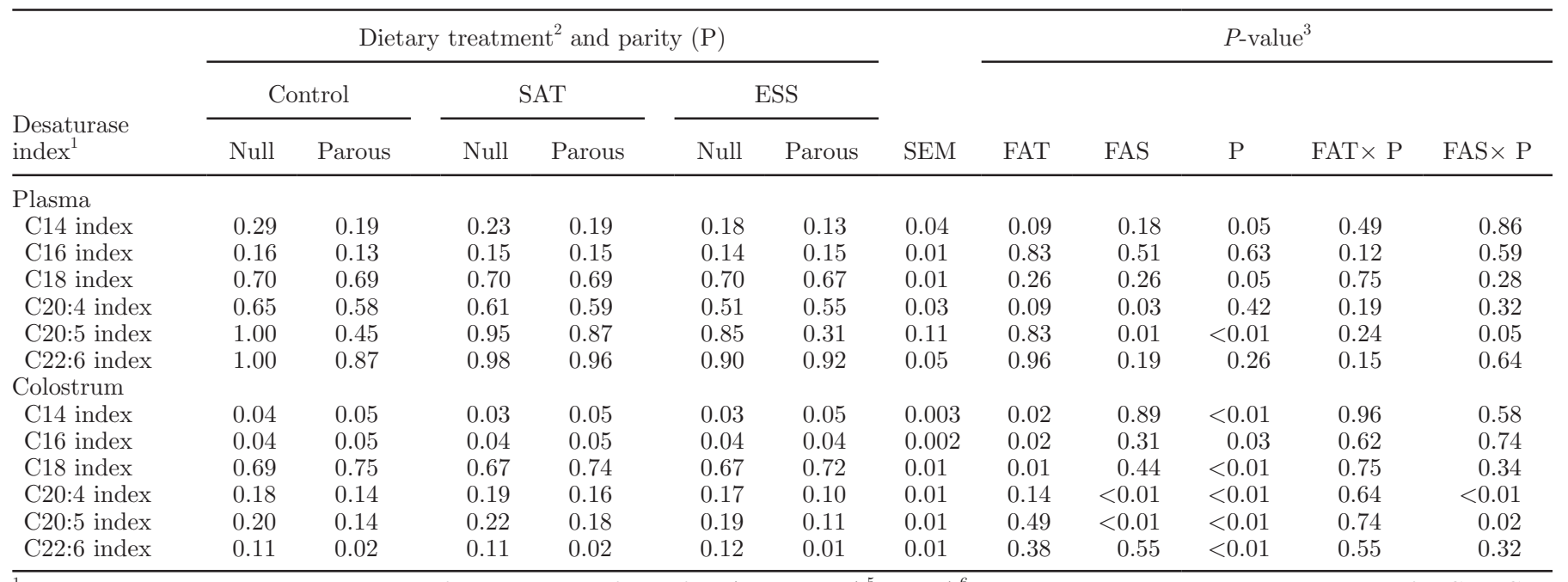

${ }^{1}$ Ratios estimated to assess the extent of desaturation of specific FA by both $\Delta^{5}$ - and $\Delta^{6}$-desaturase enzymes. Desaturase indices for C14, C16, and C18 account for the activity of $\Delta^{9}$-desaturase. Desaturase indices of C20:4n-6, C20:5n-3, and C22:6n-3 account for the combined activity of $\Delta^{5}$ - and $\Delta^{6}$-desaturases. The desaturase product is divided by the sum of desaturase product and the substrate (Loor and Herbein, 2003). As an example, C20:5n-3 index $=\mathrm{C} 20: 5 \mathrm{n}-3 /(\mathrm{C} 20: 5 \mathrm{n}-3+\mathrm{C} 18: 3 \mathrm{n}-3)$.

${ }^{2}$ Control = no fat supplement; SAT = Energy Booster 100 (Milk Specialties, Dundee, IL); ESS = Megalac-R (Church \& Dwight, Princeton, NJ). ${ }^{3} P$-values for orthogonal contrasts and interactions. FAT $=$ control vs. $(\mathrm{SAT}+\mathrm{ESS})$, FAS $=$ ESS vs. SAT. 


\section{FA Profile of Colostrum}

Mean concentration of total FA in colostrum ranged from 5.7 to $7.8 \mathrm{~g} / 100 \mathrm{~g}$ of $\mathrm{DM}$ and was not affected by fat supplementation, fat source, or parity (Table 5). Prepartum supplementation of fat, which contained mainly 18-carbon FA (Table 1), increased the proportion of C18:0 in colostrum (9.7 vs. 8.3\% of total FA, $P<0.01)$. Likewise, C18:0 was greater in colostrum from cows fed a fat supplement enriched in unsaturated 18-carbon FA compared with C16:0 (Santschi et al., 2009). This result reflects the partial biohydrogenation of unsaturated 18-carbon FA in the ESS supplement by ruminal microorganisms. De novo synthesis of short- to medium-chain FA was not affected by treatments. Concentrations of $\mathrm{C} 14: 1$ cis-9 and C16:1 cis-9 were lower $(P \leq 0.01)$ in colostrum of dams fed fat regardless of the FA source. Estimation of $\Delta^{9}$-desaturase activity by measuring the $\mathrm{C} 14$ and $\mathrm{C} 16$ indices (Table 4) indicates that dams fed either source of fat had reduced $\Delta^{9}$ desaturase activity compared with dams fed control.

Seven C18:1 trans FA isomers were identified in colostrum, ranging in mean proportion from $0.006 \%$ (C18:1 trans-5) to $1.33 \%$ (C18:1 trans-11) of FA (Table 5). All 7 identified C18:1 trans isomers were greater $(P \leq 0.03)$ in colostrum from dams fed ESS compared with those fed SAT. Similarly, C18:2 cis-9,trans-11 was greater $(P$ $<0.01)$ in ESS-fed compared with SAT-fed dams. These increases in C18:1 trans isomers agree with increases in colostrum produced by dairy cows supplemented with extruded linseed compared with a palm oil-based product (Santschi et al., 2009). Increased concentrations of trans isomers of unsaturated monoene and diene FA detected in colostrum of dams fed ESS indicates that the Ca salt product fed was not completely ruminally inert, allowing some of the C18:2n- 6 to be metabolized by ruminal microorganisms (Lundy et al., 2004).

Mean proportion of n- 6 PUFA ranged from 3.0 to $4.4 \%$ of colostral FA (Table 5). Proportion of total n-6 PUFA was greater $(P<0.01)$ in colostrum from dams fed ESS compared with those fed SAT (4.33 vs. $3.12 \%$ of $\mathrm{FA}$ ); however, only $\mathrm{C} 18: 2 \mathrm{n}-6$ and $\mathrm{C} 20: 2 \mathrm{n}-6$ were greater $(P<0.01)$ across parities. These results are evidence that ESS supplement provided some ruminally inert C18:2n-6. Other n-6 PUFA (C20:3n-6, C20:4n-6, and C22:4n-6) were increased in colostrum from nulliparous dams fed ESS compared with those fed SAT but these n-6 PUFA were not changed in colostrum of parous dams by type of fat supplement $(P$ $\leq 0.02$; FAS $\times$ parity interaction). The $\mathrm{C} 18: 2 \mathrm{n}-6$ in colostral fat produced by ewes also increased from $<1$ to $8 \%$ when the ewes were fed formaldehyde-treated soybeans (Noble et al., 1978), an oilseed enriched in C18:2n-6. In the current study, the C20:4n-6 index was lower for dams supplemented with ESS compared with those supplemented with SAT (0.14 vs. 0.18), with the decrease being greater for parous dams $(0.10$ vs. 0.16 , parity $\times$ FAS interaction, $P<0.01$, Table 4 ), which agrees with milk indices of cows fed safflower oil compared with those fed high oleic sunflower oil (Loor and Herbein, 2003).

Total n-3 PUFA made up $<1 \%$ of all FA in colostrum (Table 5) and were slightly greater in colostrum of dams fed fat compared with no fat (0.79 vs. $0.72 \%$, $P=0.04)$, although the only individual n-3 FA to be increased was $\mathrm{C} 22: 5 \mathrm{n}-3$ (0.27 vs. $0.24 \%, P=0.01)$. Fat source did not influence proportions of C18:3n-3, C20:3n-3, or C22:6n-3 in colostrum, but C20:5n-3 was in lower proportion in colostrum of dams fed ESS compared with those fed SAT (0.08 vs. $0.10 \% ; P<0.01)$. On the other hand, C22:5n-3 was greater in colostrum from nulliparous dams fed ESS compared with SAT (0.37 vs. $0.43 \%$ ) but C22:5n-3 was unaffected by fat source in colostrum from parous dams (0.16 vs. $0.13 \%$, FAS by parity interaction, $P=0.02$ ). The proportion of C18:3n-3 was increased in colostrum of cows fed linseed compared with sunflower seed prepartum (Leiber et al., 2011), reflecting the greater intake of C18:3n-3 supplied by linseed without affecting the proportions of C20:5n-3. The desaturation index for C20:5n-3 synthesis was lower for dams fed ESS compared with SAT (0.15 vs. $0.20, P<0.01$ ), with a more dramatic decrease for parous dams fed ESS compared with SAT (0.11 vs. 0.18 , parity by FAS interaction, $P=0.02$, Table 4 ). This decrease may reflect a reduction in desaturation of $\mathrm{C} 18: 3 \mathrm{n}-3$ due to a greater competition of $\mathrm{C} 18: 2 \mathrm{n}-6$ for $\Delta^{6}$-desaturase.

The dietary FA consumed by the dams is reflected in the FA profile in both plasma of newborns and colostrum of dams. However, the differential proportions of essential FA and their derivatives in these biological fluids suggest that the transfer and synthesis of these FA are under tighter regulation in placental than in mammary tissue. Although the number of C18:2n-6 derivatives modified by the feeding of ESS compared with SAT was greater in colostrum than in plasma and that of modified C18:3n-3 derivatives was greater in plasma, the actual ability of tissues to convert parent essential FA to their derivatives is better understood by their desaturase indices. The conclusion that the activity of $\Delta^{5}$ - and $\Delta^{6}$-desaturases was greater in placental than in mammary tissue is based upon the greater indices calculated for C20:4n-6, C20:5n-3, and C22:6n-3 (Table 4) in newborn plasma. In addition, synthesis of C18:3n-3 to C20:5n-3 and C22:6n-3 (0.74 and 0.94, respectively) appears to be prioritized over the synthesis of C18:2n-6 to $\mathrm{C} 20: 4 \mathrm{n}-6$ (0.58). This priority was not apparent in the mammary gland, with mean desaturation indices 
Table 5. Mean concentration of fatty acids (FA) in colostrum from nulliparous (Null) and parous Holstein animals $(\mathrm{n}=70)$ not supplemented (control) or supplemented with saturated (SAT) or essential (ESS) fatty acids starting 8 wk before calculated parturition date

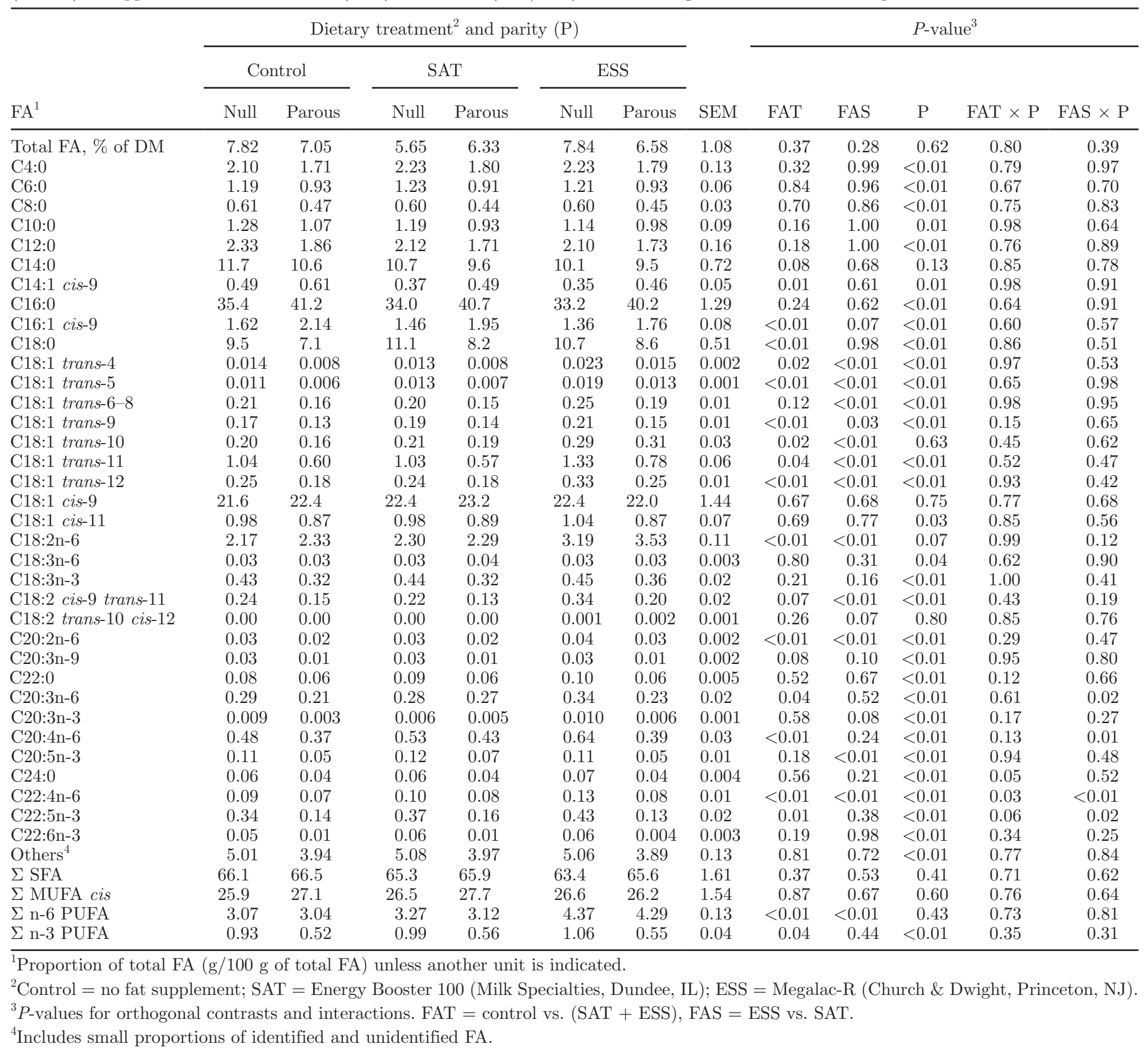

of $0.16,0.18$, and 0.06 for $\mathrm{C} 20: 4 \mathrm{n}-6, \mathrm{C} 20: 5 \mathrm{n}-3$, and C22:6n-3 across treatments, respectively. The placenta of pregnant cows appears to tightly regulate the transfer and synthesis of essential FA derivatives to meet the need of their newborns. However, in both placenta and colostrum, it appears that the supplementing of ESS reduced the activity of desaturases for synthesis of n-3 derivatives.

Parity had a marked effect on the FA profile of colostrum. Nulliparous dams produced colostrum containing less $\mathrm{C} 16: 0$ (34.2 vs. $41.7 \%$ of FA, $P<0.01$ ) but more C18:0 (10.4 vs. $8.0 \%$ of FA, $P<0.01$; Table 5 ) compared with parous dams, which resulted in no effect of parity on total SAT. All of the 7 identified C18:1 trans FA isomers except C18:1 trans-10 and C18:2 cis-9,trans-11 were in greater $(P<0.01)$ proportions in colostrum from nulliparous compared with parous dams. The proportion of $\mathrm{C} 18: 2 \mathrm{n}-6$, which accounted for $\sim 74 \%$ of total n- 6 PUFA, tended to be lower $(P=0.07)$ in nulliparous compared with parous dams (2.55 vs. 
$2.72 \%$ ). This effect of parity on C18:2n-6 in colostrum was similar to that in plasma. However, all elongated derivatives of $\mathrm{C} 18: 2 \mathrm{n}-6$ except $\mathrm{C} 18: 3 \mathrm{n}-6$ were greater $(P \leq 0.01)$ in colostrum from nulliparous dams, which is the exact opposite of that detected for plasma. The effect of parity on individual n-3 PUFA in colostrum was the same as it was in plasma. Nulliparous dams produced colostrum fat with greater $(P<0.01)$ n-3 FA than parous dams. In agreement with the current findings, Mierlita et al. (2011) reported increased proportions of $\mathrm{C} 18: 3 \mathrm{n}-3$ and $\mathrm{C} 20: 5 \mathrm{n}-3$ in milk fat produced by primiparous compared with multiparous ewes. Nulliparous dams had greater desaturase indices for C20:4n-6, C20:5n-3, and C22:6n-3 (Table 4) compared with parous dams $(P<0.01)$, demonstrating less ability to synthesize essential FA derivatives by older cows. In rats, overall $\Delta^{6}$-desaturase activity was depressed with age (Hrelia et al., 1989). This would suggest that offspring born to first-lactation cows may have better development of their central nervous systems.

\section{Calf Absorption of Colostral lgG}

Calves born from parous dams supplemented with fat tended to be heavier at birth than those born from control parous dams (43.7 vs. $39.8 \mathrm{~kg}$ ), whereas prepartum fat supplementation did not influence the birth weight of calves born to nulliparous dams (36.6 vs. 37.2 kg; parity by FAT interaction, $P=0.06$; Table 6 ). Although the increased birth weight occurred without an increased daily intake of $\mathrm{NE}_{\mathrm{L}}$ or increased number of gestation days, numerical increases were noted for both variables (Table 2). Feeding more energy-dense diets $\left(1.25,1.40\right.$, and $1.55 \mathrm{Mcal}$ of $\mathrm{NE}_{\mathrm{L}} / \mathrm{kg}$ of $\left.\mathrm{DM}\right)$ to multiparous cows during the last $21 \mathrm{~d}$ of gestation tended to linearly increase the birth weight of calves (Gao et al., 2012). This parity by dietary fat effect on birth weight may result from heifers utilizing dietary energy for their own growth plus growth of the fetus, whereas mature cows can direct energy to the fetus alone, leading to heavier calves at birth.

Fat source did not affect calf birth weight. Feeding isocaloric and isonitrogenous diets enriched or not with C18:2n-6 to mid- to late-gestation beef heifers or multiparous beef cows did not affect the BW at birth of their newborns (Dietz et al., 2003).

As expected, male calves were heavier $(P=0.02)$ than female calves at birth (41.0 vs. $38.2 \mathrm{~kg}$; data not shown). Male calves born from dams fed SAT tended to be heavier than those born from dams fed ESS (43.2 vs. $39.6 \mathrm{~kg}$ ), whereas prepartum fat source did not affect the birth weight of female calves ( 38.3 vs. $39.7 \mathrm{~kg}$, sex by FAT interaction, $P=0.06$; data not shown). Dams supplemented with SAT and delivering male calves consumed 1.3 Mcal/d more NEL than dams supplemented with ESS, although this difference was not significant, which may partially explain this interaction.

All calves were fed $4 \mathrm{~L}$ of colostrum; hence, intake of $\mathrm{IgG}$ by calves reflected the concentration of $\operatorname{IgG}$ in the consumed colostrum (Table 2). Despite differences

Table 6. Passive immunity related measures in calves born from nulliparous (Null) and parous Holstein animals not supplemented (control) or supplemented with saturated (SAT) or essential (ESS) fatty acids starting 8 wk before calculated parturition date

\begin{tabular}{|c|c|c|c|c|c|c|c|c|c|c|c|c|}
\hline \multirow{2}{*}{ Measure } & \multicolumn{6}{|c|}{ Dietary treatment ${ }^{1}$ and parity $(\mathrm{P})$} & \multirow{2}{*}{ SEM } & \multirow{2}{*}{ FAT } & \multicolumn{3}{|c|}{$P$-value ${ }^{2}$} & \multirow{2}{*}{$\mathrm{FAS} \times \mathrm{P}$} \\
\hline & \multicolumn{2}{|c|}{ Control } & \multicolumn{2}{|c|}{ SAT } & \multicolumn{2}{|c|}{ ESS } & & & & & & \\
\hline Number of calves & 8 & 17 & 11 & 16 & 9 & 17 & & & & & & \\
\hline Birth & & & & & & & & & & & & \\
\hline $\mathrm{BW},{ }^{3} \mathrm{~kg}$ & 37.2 & 39.8 & 37.8 & 43.7 & 35.5 & 43.8 & 1.32 & 0.13 & 0.40 & $<0.01$ & 0.06 & 0.38 \\
\hline Serum IgG, g/L & 0.20 & 0.20 & 0.30 & 0.20 & 0.10 & 0.20 & 0.01 & 0.77 & 0.34 & 0.95 & 0.66 & 0.44 \\
\hline $24 \mathrm{~h}$ after birth & & & & & & & & & & & & \\
\hline STP, g/dL & 6.35 & 6.16 & 6.21 & 6.58 & 6.33 & 6.23 & 0.21 & 0.67 & 0.59 & 0.90 & 0.39 & 0.25 \\
\hline Serum $\operatorname{IgG},{ }^{5} \mathrm{~g} / \mathrm{L}$ & 24.0 & 22.1 & 26.9 & 29.7 & 25.1 & 23.6 & 2.20 & 0.09 & 0.07 & 0.90 & 0.52 & 0.32 \\
\hline Serum IgG, $\%$ of STP & 37.4 & 35.2 & 42.3 & 44.6 & 39.1 & 37.3 & 2.57 & 0.05 & 0.05 & 0.79 & 0.59 & 0.42 \\
\hline $\mathrm{AEA},{ }^{6} \%$ & 23.7 & 23.0 & 30.5 & 28.6 & 27.3 & 25.1 & 2.27 & 0.03 & 0.14 & 0.41 & 0.73 & 0.95 \\
\hline
\end{tabular}

${ }^{1}$ Control $=$ no fat supplement; SAT $=$ Energy Booster 100 (Milk Specialties, Dundee, IL); ESS = Megalac-R (Church \& Dwight, Princeton, NJ).

${ }^{2} P$-values for orthogonal contrasts and interactions: FAT $=$ control vs. $(\mathrm{SAT}+\mathrm{ESS})$, FAS $=\mathrm{ESS}$ vs. SAT. Interactions of dietary treatments with sex were not significant unless footnoted.

${ }^{3}$ Sex, $P=0.02$, interaction of FAS and sex, $P=0.06$.

${ }^{4}$ Serum total protein.

${ }^{5}$ Interaction of FAT and sex, $P=0.03$.

${ }^{6}$ Apparent efficiency of $\operatorname{IgG}$ absorption, $\%=\{\operatorname{IgG}$ concentration in serum at $24 \mathrm{~h}$ of life $(\mathrm{g} / \mathrm{L}) \times[0.099 \times \mathrm{BW}$ at birth $(\mathrm{kg})] / \mathrm{IgG}$ intake $(\mathrm{g})\} \times$ 100 . 
in IgG intake, concentrations of STP at $24 \mathrm{~h}$ of life did not differ among treatments, ranging from 6.16 to $6.58 \mathrm{~g} / \mathrm{dL}$. Concentrations of STP correlated positively with concentrations of $\operatorname{IgG}$ in colostrum $(\mathrm{r}=0.50, P$ $<0.01)$.

Mean serum concentrations of total IgG at birth were very low, as expected $(\leq 0.3 \mathrm{~g} / \mathrm{L}$, Table 6$)$ and, in most cases, were undetectable. Almost all calves fed $4 \mathrm{~L}$ of good quality colostrum within $2 \mathrm{~h}$ of birth had $>22 \mathrm{~g} / \mathrm{L}$ of total serum IgG at 24 to $30 \mathrm{~h}$ of life, which is twice that of the minimum needed to ensure APT. Only 1 calf in the study had a serum concentration of $\operatorname{IgG}<10$ $\mathrm{g} / \mathrm{L}$ after feeding of colostrum and that from a SAT-fed dam.

Mean serum concentration of total IgG at 24 to 30 $\mathrm{h}$ after feeding of colostrum was lower in male calves born from dams not fed fat compared with those born from dams fed fat $(20.3$ vs. $27.8 \mathrm{~g} / \mathrm{L}$, whereas that of female calves did not differ (25.1 vs. $24.4 \mathrm{~g} / \mathrm{L}$, sex by FAT interaction, $P=0.03$ ). This interaction may be explained by the negative relationship between intake of IgG and efficiency of absorption of IgG reported by Besser et al. (1985) and documented in the current study $(\mathrm{r}=-0.40, P<0.01)$. Reports have been mixed as to whether sex influences circulating concentrations of IgG (Quigley and Drewry, 1998).

Regardless of sex, calves born from dams fed SAT tended $(P=0.07)$ to have greater serum concentrations of total IgG after colostrum feeding than those born from dams fed ESS (28.3 vs. $24.3 \mathrm{~g} / \mathrm{L}$, Table 6). This trend became significant $(P=0.05)$ when total serum IgG was expressed as a proportion of STP (43.5 vs. $38.2 \%)$. Supplementation of oilseeds enriched in C18:2n-6 to mature beef cows did not change concentration of IgG in serum of suckling beef calves compared with calves suckling cows not fed oilseeds (Dietz et al., 2003). A saturated fat was not used in that study. Calves born to beef heifers in better body condition ( $\geq 5$ BCS) had greater serum concentrations of $\operatorname{IgG}$, although it could not be determined if the increase was due to greater IgG in colostrum or greater intake of colostrum by the nursing calves (Odde, 1988). The AEA of IgG consumed did not differ between calves born from dams fed SAT or ESS $(P=0.14)$ but calves born from dams fed fat had better $(P=0.03)$ AEA than calves born from control dams (27.9 vs. $23.3 \%$, Table $6)$. Based upon multiple means testing, no difference $(P$ $=0.21$ ) in AEA was detected between calves born from control and ESS dams, whereas AEA of calves born from dams fed SAT was greater $(P=0.01)$ than that of control calves. The most distinct treatment effect on AEA was that due to SAT supplementation.

Factors that may influence AEA include age of calf at time of $\operatorname{IgG}$ intake, amount of IgG consumed, rate of gastric emptying, and absorptive capacity of enterocytes for IgG. First, all calves received IgG within $2 \mathrm{~h}$ of life, thus eliminating age of calf as an explanatory factor. Second, Besser et al. (1985) reported a negative relationship between intake of IgG and efficiency of absorption of IgG. This relationship was evident for calves born from nulliparous dams supplemented with SAT but not for those born from parous dams (Table 6 ), so this may partially explain the better AEA coefficients for calves born to SAT-supplemented dams. Third, greater efficiency of IgG absorption occurred in neonatal Holstein-Friesian calves that experienced a faster rate of gastric emptying (Mokhber-Dezfooli et al., 2012). A slower rate of gastric emptying was reported for calves duodenally infused with fat compared with lactose or casein (Bell and McLeay, 1978). In the current study, the concentration of FA in colostrum from SAT-supplemented dams was numerically lowest (7.4, 5.9 , and $7.2 \%$ for control, SAT, and ESS treatments, respectively, Table 5). Thus, the abomasum of calves born to SAT-supplemented dams may have retained colostrum for a shorter period, delivering IgG to the small intestine more quickly and contributing to a more efficient IgG absorption. In addition, type of FA may affect rate of gastric emptying. Women that consumed n-3 FA experienced a faster rate of gastric emptying compared with those consuming additional MUFA or SFA (Robertson et al., 2002). Intake of n-3 FA was $13 \%$ greater by calves born from dams fed SAT or ESS compared with control calves due to a greater concentration of n-3 PUFA in colostrum (Table 5), which may have increased gastric emptying in the former calves. Finally, a plausible mechanism behind the increase in circulating $\operatorname{IgG}$ concentrations in calves born from dams fed SAT is FA changes in the enterocyte membrane, which may influence microdomain organization. Ingested IgG are taken up nonspecifically by endothelial cells via pinocytosis that is receptor-independent in ruminants (Cervenak and Kacskovics, 2009). The bending of the cell membrane during pinocytosis requires "curvature-inducing" proteins and "modification or clustering of membrane lipids," although the exact method of membrane shaping has remained elusive (Krauss and Haucke, 2011). Because IgG absorption is receptor-independent in ruminants, the ability of the cell to internalize IgG may depend upon cell formation of nanoscale membrane microdomains enriched in cholesterol and glycosphingolipids (Krauss and Haucke, 2011). The first step in glycosphingolipid biosynthesis is the condensation of serine and palmitoyl-CoA. The FA of the final product vary in chain length and unsaturation but in mammals they are mostly $\geq \mathrm{C} 16$ and saturated (Degroote et al., 2004). Therefore, it is reasonable to postulate that supplementing SAT during 
the prepartum period may increase synthesis or change FA composition of sphingolipids, which may impart greater stability to the lipid rafts. Indeed, the FA profile of plasma of calves born from nulliparous dams fed SAT or ESS had a greater proportion of C14:0 and C16:0 (Table 3). In addition, the FA of colostrum from dams fed SAT or ESS contained more C18:0 (Table 5). Future studies to identify the mechanisms by which prepartum supplementation of fat may modify the efficiency $\operatorname{IgG}$ absorption are warranted.

\section{CONCLUSIONS}

Including $1.7 \% \mathrm{FA}$ as SAT or ESS in low-FA diets (2.0\% of dietary DM) during the last 8 wk of gestation can influence the immunoglobulin status of the newborn calf. Supplementing fat prepartum had no effect on DMI, BW gain, change in BCS, or gestation length of dams, but birth weight of calves born from parous dams was increased by fat supplementation. Supplementing fat enriched in $\mathrm{C} 18: 2 \mathrm{n}-6$ rather than $\mathrm{C} 18: 0$ tended to increase concentration of total FA in plasma of calves at birth (1.36 vs. $1.22 \mathrm{mg} / \mathrm{mL})$. In addition, the transfer and synthesis of elongated n-3 PUFA (C20:5, C22:5, and $\mathrm{C} 22: 6$ ) by placenta were decreased, whereas the n-6 PUFA (C18:2, C18:3, and C20:3) were increased in plasma of calves born from dams fed ESS rather than SAT. The FA profile of colostrum was modified to a greater degree by prepartum fat feeding than was that of plasma of newborns, suggesting that the metabolism and transfer of essential FA from the placenta to the fetus is under tighter regulation than the metabolism and transfer of FA from the mammary gland to colostrum. Increased concentrations of trans isomers of unsaturated monoene and diene FA were detected in colostrum of dams fed ESS. Circulating concentrations of serum IgG were greater in calves born from dams fed SAT due to greater apparent efficiency of absorption of IgG from the small intestine.

\section{ACKNOWLEDGMENTS}

The help of the entire staff at the University of Florida Dairy Research Unit (Hague) is appreciated deeply. Graduate students Fabio Lima, Eduardo Ribeiro, and Dan Wang provided valuable help with field activities, and Courtney Preseault assisted with colostrum FA analysis. Arm and Hammer Nutrition (Princeton, NJ) is gratefully acknowledged for partial funding of the study.

\section{REFERENCES}

Al, M. D. M., A. C. van Houwelingen, and G. Hornstra. 1997. Relation between birth order and the maternal and neonatal docosahexaenoic acid status. Eur. J. Clin. Nutr. 51:548-553.
Bancroft, T. A. 1968. Topics in Intermediate Statistical Methods. Iowa State University Press, Ames.

Bell, F. R., and L. M. McLeay. 1978. The effect of duodenal infusion of milk, casein, lactose and fat on gastric emptying and acid secretion in the milk-fed calf. J. Physiol. 282:51-57.

Besser, T. E., A. E. Garmedia, T. C. McGuire, and C. C. Gay. 1985. Effect of colostral immunoglobulin $\mathrm{G}_{1}$ and immunoglobulin $\mathrm{M}$ concentrations on immunoglobulin absorption in calves. J. Dairy Sci. 68:2033-2037.

Bradbury, J. 2011. Docosahexaenoic acid (DHA): An ancient nutrient for the modern human brain. Nutrients 3:529-554.

Caldari-Torres, C., A. L. Lock, C. R. Staples, and L. Badinga. 2011. Performance, metabolic, and endocrine responses of periparturient Holstein cows fed 3 sources of fat. J. Dairy Sci. 94:1500-1510.

Cervenak, J., and I. Kacskovics. 2009. The neonatal Fc receptor plays a crucial role in the metabolism of IgG in livestock animals. Vet. Immunol. Immunopathol. 128:171-177.

Degroote, S., J. Wolthoorn, and G. van Meer. 2004. The cell biology of glycosphingolipids. Semin. Cell Dev. Biol. 15:375-387.

Dewhurst, R. J., K. J. Shingfield, M. R. F. Lee, and N. D. Scollan. 2006. Increasing the concentrations of beneficial polyunsaturated fatty acids in milk produced by dairy cows in high-forage systems. Anim. Feed Sci. Technol. 131:168-206.

Dietz, R. E., J. B. Hall, W. D. Whittier, F. Elvinger, and D. E. Eversole. 2003. Effects of feeding supplemental fat to beef cows on cold tolerance in newborn calves. J. Anim. Sci. 81:885-894.

Drackley, J. K. 1999. Biology of dairy cows during the transition period: The final frontier? J. Dairy Sci. 82:2259-2273.

Edidin, M. 2003. The state of lipid rafts: From model membranes to cells. Annu. Rev. Biophys. Biomol. Struct. 32:257-283.

Elanco. 1996. Body condition scoring in dairy cattle. Elanco Animal Health Bull. AI8478. Elanco Animal Health, Greenfield, IN.

Elmes, M., P. Tew, Z. Cheng, S. E. Kirkup, D. R. E. Abayasekara, P. C. Calder, M. A. Hanson, D. C. Wathes, and G. C. Burdge. 2004. The effect of dietary supplementation with linoleic acid to late gestation ewes on the fatty acid composition of maternal and fetal plasma and tissues and the synthetic capacity of the placenta for 2-series prostaglandins. Biochim. Biophys. Acta 1686:139-147.

Gao, F., Y. C. Liu, Z. H. Zhang, C. Z. Zhang, H. W. Su, and S. L. Li. 2012. Effect of prepartum maternal energy density on the growth performance, immunity, and antioxidation capability of neonatal calves. J. Dairy Sci. 95:4510-4518.

Hrelia, S., A. Bordoni, M. Celadon, E. Turchetto, P. L. Biagi, and C. A. Rossi. 1989. Age-related changes in linoleate and alpha-linolenate desaturation by rat liver microsomes. Biochem. Biophys. Res. Commun. 163:348-355.

Jacobi, S. K., and J. Odle. 2012. Nutritional factors influencing intestinal health of the neonate. Adv. Nutr. 3:687-696.

Jenkins, K. J., G. Griffith, and I. K. G. Kramer. 1988. Plasma lipoproteins in neonatal, preruminant, and weaned calf. J. Dairy Sci. 71:3003-3012.

Kim, S. C., A. T. Adesogan, L. Badinga, and C. R. Staples. 2007. Effects of dietary n-6:n-3 fatty acid ratio on feed intake, digestibility, and fatty acid profiles of the ruminal contents, liver, and muscle of growing lambs. J. Anim. Sci. 85:706-716.

Klusmeyer, T. H., and J. H. Clark. 1991. Effects of dietary fat and protein on fatty acid flow to the duodenum and in milk produced by dairy cows. J. Dairy Sci. 74:3055-3067.

Kramer, J. K. G., C. Cruz-Hernandez, and J. Q. Zhou. 2001. Conjugated linoleic acids and octadecenoic acids: Analysis by GC. Eur. J. Lipid Sci. Technol. 103:600-609.

Kramer, J. K. G., V. Fellner, M. E. R. Dugan, F. D. Sauer, M. M. Mossoba, and M. P. Yurawecz. 1997. Evaluating acid and base catalysts in the methylation of milk and rumen fatty acids with special emphasis on conjugated dienes and total trans fatty acids. Lipids 32:1219-1228.

Krauss, M., and V. Haucke. 2011. Shaping membranes for endocytosis. Rev. Physiol. Biochem. Pharmacol. 161:45-66.

Lecce, J. G. 1965-1966. Absorption of macromolecules by neonatal intestine. Biol. Neonat. 9:50-61. 
Leiber, F., R. Hochstrasser, H. R. Wettstein, and M. Kreuzer. 2011. Feeding transition cows with oilseeds: effects on fatty acid composition of adipose tissue, colostrum and milk. Livest. Sci. 138:1-12.

Liou, Y. A., D. J. King, D. Zibrik, and S. M. Innis. 2007. Decreasing linoleic acid with constant alpha-linolenic acid in dietary fats increases (n-3) eicosapentaenoic acid in plasma phospholipids in healthy men. J. Nutr. 137:945-952.

Loor, J. J., and J. H. Herbein. 2003. Reduced fatty acid synthesis and desaturation due to exogenous trans10, cis12-CLA in cows fed oleic or linoleic oil. J. Dairy Sci. 86:1354-1369.

Lundy, F. P., III, E. Block, W. C. Bridges Jr., J. A. Bertrand, and T. C. Jenkins. 2004. Ruminal biohydrogenation in Holstein cows fed soybean fatty acids as amides or calcium salts. J. Dairy Sci. 87:1038-1046

Mierlita, D., I. Padeanu, C. Maerescu, I. Chereji, E. Halma, and F. Lup. 2011. Comparative study regarding the fatty acids profile in sheep milk related to the breed and parity. Anim. Husb. Technol. Food Indus. 10:221-232.

Moallem, U., and M. Zachut. 2012. Short communication: The effects of supplementation of various n-3 fatty acids to late-pregnant dairy cows on plasma fatty acid composition of the newborn calves. J. Dairy Sci. 95:4055-4058.

Mokhber-Dezfooli, M. R., M. Nouri, M. Rasekh, and P. D. Constable. 2012. Effect of abomasal emptying rate on the apparent efficiency of colostral immunoglobulin G absorption in neonatal HolsteinFriesian calves. J. Dairy Sci. 95:6740-6749.

Noble, R. C., J. H. Shand, and W. W. Christie. 1985. Synthesis of C20 and C22 polyunsaturated fatty acids by the placenta of the sheep. Biol. Neonate 47:333-338.

Noble, R. C., J. H. Shand, J. T. Drummond, and J. H. Moore. 1978. "Protected" polyunsaturated fatty acid in the diet of the ewe and the essential fatty acid status of the neonatal lamb. J. Nutr. 108:1868-1876.

Odde, K. G. 1988. Survival of the neonatal calf. Vet. Clin. North Am. Food Anim. Pract. 4:501-508.

Onetti, S. G., and R. R. Grummer. 2004. Response of lactating cows to three supplemental fat sources as affected by forage in the diet and stage of lactation: A meta-analysis of literature. Anim. Feed Sci. Technol. 115:65-82.
Onetti, S. G., R. D. Shaver, M. A. McGuire, and R. R. Grummer. 2001. Effect of type and level of dietary fat on rumen fermentation and performance of dairy cows fed corn silage-based diets. J. Dairy Sci. 84:2751-2759.

Payne, E. 1978. Fatty acid composition of tissue phospholipids of the foetal calf and neonatal lamb, deer calf and piglet as compared with the cow, sheep, deer and pig. Br. J. Nutr. 39:45-52.

Quigley, J. D., III, and J. J. Drewry. 1998. Nutrient and immunity transfer from cow to calf pre- and postcalving. J. Dairy Sci. 81:2779-2790.

Quigley, J. D., III, J. J. Drewry, and K. R. Martin. 1998. Estimation of plasma volume in Holstein and Jersey calves. J. Dairy Sci. 81:1308-1312

Relling, A. E., and C. K. Reynolds. 2007. Feeding rumen-inert fats differing in their degree of saturation decreases intake and increases plasma concentrations of gut peptides in lactating dairy cows. J. Dairy Sci. 90:1506-1515.

Robertson, M. D., K. G. Jackson, B. A. Fielding, L. M. Morgan, C. M. Williams, and K. N. Frayn. 2002. Acute ingestion of a meal rich in n-3 polyunsaturated fatty acids results in rapid gastric emptying in humans. Am. J. Clin. Nutr. 76:232-238.

Santschi, D. E. H. R. Wettstein, F. Leiber, A. K. M. Witschi, and K. Kreuzer. 2009. Colostrum and milk fatty acids of dairy cows as influenced by extruded linseed supplementation during the transition period. Can. J. Anim. Sci. 89:383-392.

Soares, M. C. 1986. Effect of dietary protected lipids on the essential fatty acid status of the newborn kid. J. Nutr. 116:1473-1479.

Tyler, J. W., D. D. Hancock, S. M. Parish, D. E. Rea, T. E. Besser, S G. Sanders, and L. K. Wilson. 1996. Evaluation of 3 assays for failure of passive transfer in calves. J. Vet. Intern. Med. 10:304-307.

Ulberth, F., and F. Schrammel. 1995. Accurate quantitation of short chain, medium-chain, and long-chain fatty acid methyl-esters by split-injection capillary gas-chromatography. J. Chromatogr. A 704:455-463.

Van Soest, P. J., J. B. Robertson, and B. A. Lewis. 1991. Methods for dietary fiber, neutral detergent fiber and nonstarch polysaccharides in relation to animal nutrition. J. Dairy Sci. 74:3583-3597. 